مجلة التربية والعلم ، المجلد 28 ، العدد 2 ، 2019: 150-166

\title{
Anotomical and Histological Comparative Study of The Proventriculus and Histochmisitry of Mucins in Two Species of Birds Which Differ in Nutrient Nature
}

\author{
Ameer Mahmood Taha Al-Hamdany \\ amhamdany@gmail.com \\ Abdulaziz Subhi Aziz Ali AL duleemy \\ azia.subhi1987@gmail.com \\ University of Mosul/ College of Education for Pure Science/ Department of biology
}

$\begin{array}{cc}\text { Received } & \text { Accepted } \\ \text { 21/10/2018 } & 03 / 12 / 2018\end{array}$

\begin{abstract}
The present study aimed to identify the anatomical and histological aspects as well as the histochemistery of mucin of glandular stomach of two birds which differ in their feeding habit. These birds are Sturnus vulgaris and Taenipygia guttat using light microscope and histochemical techniques. The anatomical results showed that the glandular stomach in Taenipygia guttat was conical or elongated while it was conical shape in the Sturnus vulgaris. Histologically, the result showed that the wall of the glandular stomach in both birds composed of four layers that comprise the rest of the digestive canal, The mucous layer of the glandular stomach in the two birds consist of folds extending into the glandular stomach cavity which known as mucus folds which is lined by simple epithelial columnar tissue, below it lies the lamina properia which contains superficial glands. While Submucosa is fully occupied with deep gastric glands. Muscularis consist of two layers, The internal circular shape and external longitudinal shape, as well as the serosa covered by mesothelim. Histochemically, the epithelial tissue showed moderate positive response for PAS reaction in both birds indicating the presence of moderate quantities of positive mucus materials for PAS reaction

For TB technique epithelial tissue showed a positive response in $T$. guttat indicating that there is relatively large amounts of acidic mucopolysaccharides in both birds , while the epithelial tissue in $T$. guttat. and $S$. vulgaris showed positive response for $\mathrm{AB} \mathrm{PH} 1, \mathrm{AB}$ ph2.5. techniques respectively. AS for AB-PAS epithelial tissue in both birds showed a positive response indicating the presence of neutral and acidic mucins. Superficial gastric glands in both birds showed positive response for all techniques used, as well as the deep gastric glands which showed positive response in T. guttat and S. vulgaris for PAS techniques, while the AB PH2.5 and TB technique showed similar responses in both birds. AS for AB-PAS technique, positive responses as were shown in both birds, indicating large quantities of mucin in the secretions of these glands.
\end{abstract}

Key words: birds, glandular stomach, Mucus

*حث مستل من رسالة الماجستير للباحث الثاني بإثر اف الباحث الاول * 


\title{
دراسة تشريحية ونسجية مقارنة للمعدة الغدية وكيمياء النسج للمخاطين فيها لنوعين من الطيور مختلفة التغذية \\ عبدالعزيز صبحي عزيز الاليمي \\ امير محمود طه الحمداني \\ جامعة الموصل / كلية التربية للعلوم الصرفة / قسم علوم الحياة
}

$$
\text { تاريخ الاستلام 2018/10/21 }
$$

\begin{abstract}
الخلاصة
هدفت الدراسة الحالية الى التعرف على النواحي التشريحية والنسجية فضلاً عن كيمياء النسج لمخاطين المعدة الغدية في نوعين من الطيور مختلفة التغذية وهما الزرزور Sturnus Vulgaris والعصفور المبرقش Taenipygia guttat النتائج التشريحية ان المعدة الغدية في العصفور المبرقش مخروطية او منطاولة الثكل بينما كانت في الزرزور مخروطية. اما من الناحية النسجية فقد بينت النتائج ان جدران المعدة الغدية في الطائرين تتألف من الطبقات الاربع التي تتألف منها بقية اجزاء القناة الهضمية، اذ تتكون الطبقة المخاطية للمعدة الغدية في الطائرين من فئس طيات او بروزات تمتد الى داخل تجويف المعدة الغدية تعرف بالحروف المخاطية تبطن بنسيج ظهاري عمودي

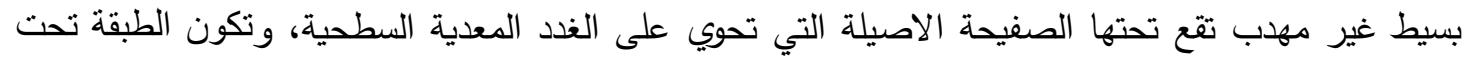
المخاطية مشغولة بالكامل بالغدد المعدية العميقة، بينما تكون الطبقة العضلية مكونة من طبقتين داخلية دائرية الشكل وخارجية طولية، اما الطبقة المصلية فتكون مكونة من نسيج ضام تغطى من الخارج بنسيج ظهاري حرشفي بسيط. اما من الناحية الكيميائية النسجية فقد اظهر النسيج الظهاري استجابة موجبة متوسطة لتقنية

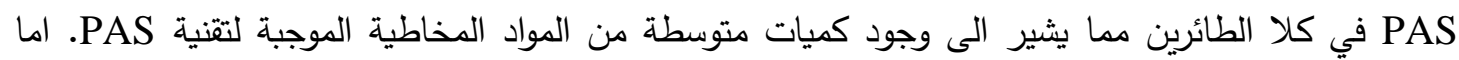
بالنسبة لتقنية TB فقد اظهر النسيج الظهاري استجابة موجبة في الطائرين مما يدل على وجود كميات كبيرة نسبياً من السكريات المتعددة المخاطية الحامضية. وقد اظهر النسيج الظهاري في الطائرين استجابة موجبة لتقنية AB PH 2.5 استجابة موجبة مما يدل على وجود المخاطين المتعادل والحامضي. اما بالنسبة للغدد المعدية السطحية في دائ الطائرين فقد اظهرت استجابة موجبة لجميع التقنيات المستعطلة. بينما اظهرت الغدد المعدية العميقة استجابة موجبة في كلا الطائرين لتقنية PAS واظهرت التقنيات TB و 2.5 و AB PH 1 و AB PH استجابات متماثلة في كلا الطائرين، اما فيما يخص تقنية AB-PAS فقد اظهرت استجابات موجبة في كلا الطائرين مما يدل على وجود كميات كبيرة من المخاطين في افرازات هذه الغدد.
\end{abstract}




\section{المقدمة}

تتكون المعدة في الطيور من جزأين يدعى الجزء الاول بالمعدة الغدية (الحقيقية) والجزء الثاني بالمعدة

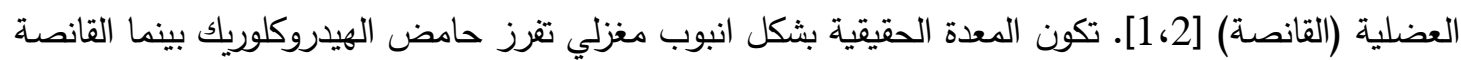
تتصل ذنبيا بالمعدة الغدية وتكون ذات شكل مدور مسطح وجدارها سميك جداً وتهضم الطعام ميكانيكياً فضلاً

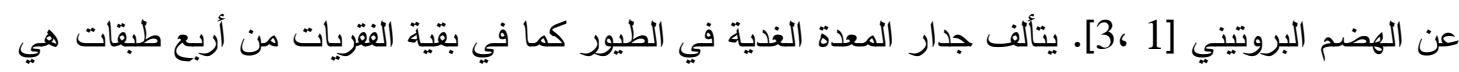
الطبقة المخاطية والطبقة تحت المخاطية والطبقة العضلية والطبقة المصلية [1، 4]. تحتوي الطبقة المخاطية

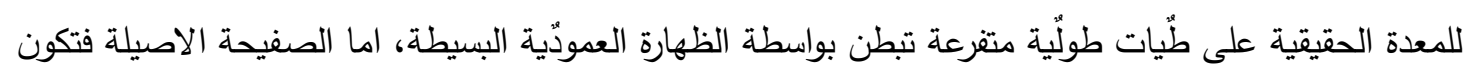
محتوية على الغدد من النوع النبيبي البسيط تكون مدعومة بالألياف العضلية للمخاطية العضلية. اما الطبقة

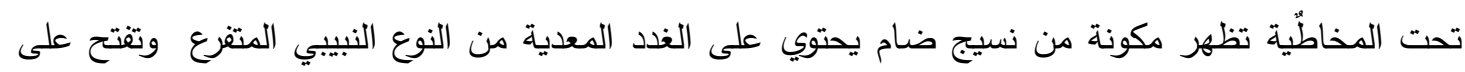

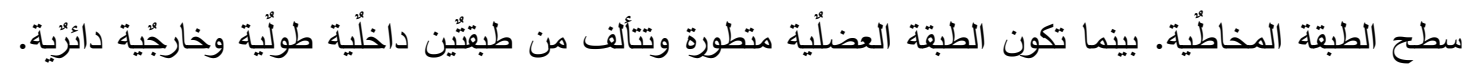

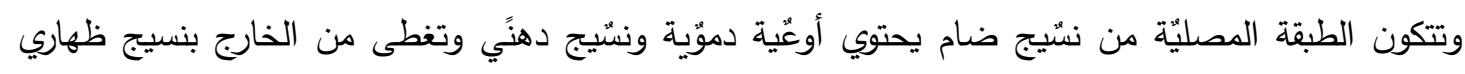

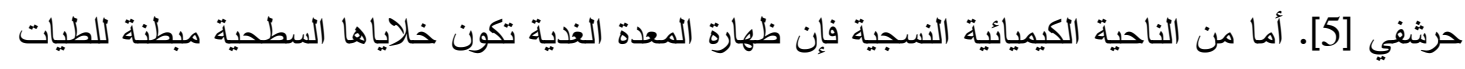

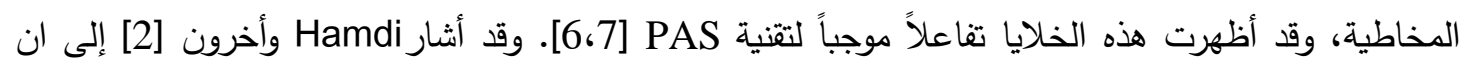
هذه الخلايا السطحية للظهارة المبطنة للطيات المخاطية تفرز سكريات متعددة مخاطية وتكون حامضية ومتعادلة لذا فهي تعطي لوناً أزرقاً وأحمراً مع صبغة PAS و AB. ومن جانب آخر فإن الخلايا القنوية المبطنة لقنوات

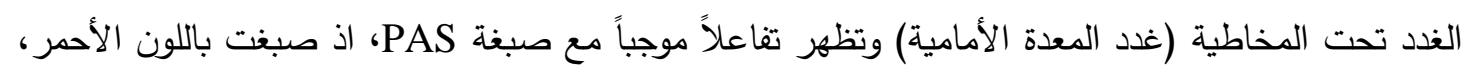
وهذا يثير إلى وجود سكريات متعددة مخاطية متعادلة. إن السكريات المتعددة المخاطية المتعادلة تكون موجودة بكثرة في الغدد المعدية، كما ان الغدد السطحية تفرز سكريات متعددة حامضية ومتعادلة، لذلك يبدو لونها أحمراً وأزرقاً عند صبغها بصبغة PAS و AB. وقد أظهرت هذه الخلايا الفة موجبة مع صبغة أزرق البرموفينول Bromophenol blue [2،7 PAS الطيور مختلفة من حيث التصنيف ونوع التغذية فضلاً عن التعرف على وجود وتوزيع المخاطين في المعدة الغدية لهذه الطيور •

\section{المواد وطرائق العمل}

تم شراء طيور العصفور المبرقش من احد محلات بيع طيور الزينة في مدينة الموصل وتم اصطياد طائر الزرزور من قبل احد صيادي الطيور في مدينة الموصل وكذلك في مدينة اربيل في اقليم كردستان العراق، وبلغ عددها عشرة لكل نوع وتم وضعها في اقفاص حديدية في غرفة تربية الحيوان في جامعة الموصل / كلية

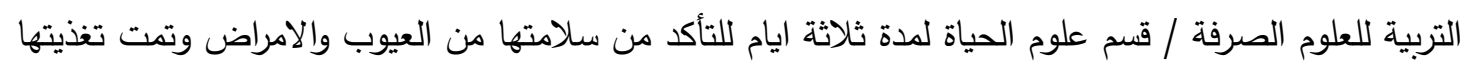
حسب نوع وطريقة تغذية كل طائر [8، 9]. بعد ذلك تم تشريح الطيور واستئصال المعدة الغدية بعناية فائقة

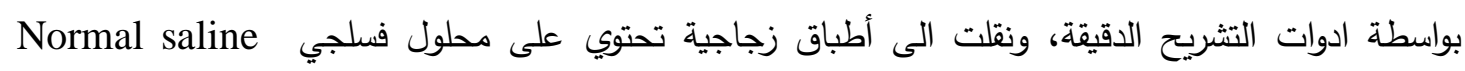

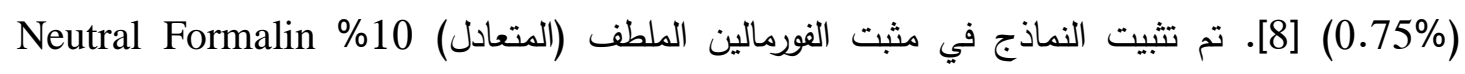
والمحضر حسب طريقة الحاج [10] ولمدة تتراوح بين 24-48 ساعة. غسلت النماذج بالماء الجاري لمدة 5 دقائق لازالة اثر المثبت. وبعدها اجريت عملية الانكاز والترويق ثم تمت عملية الطمر في شمع البرافين [10] ـ

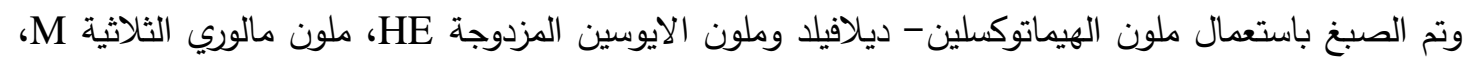


تقنية الاليشيان الازرق PH و PH PH 2.5 1 PB تقنية حامض البريوديك- شيف PAS، تقنية ازرق التلودين

Tوتقنية PAS-AB

\section{النتائج}

ظهرت المعدة الغدية من الناحية التشريحية مخروطية او متطاولة الثكل في العصفور المبرقش قتها باتجاه المريء وقاعدتها باتجاه القانصة وتكون جدرانها ذات تجهيز دموي عالٍ (الصورة:1). وتتبعج من الداخل

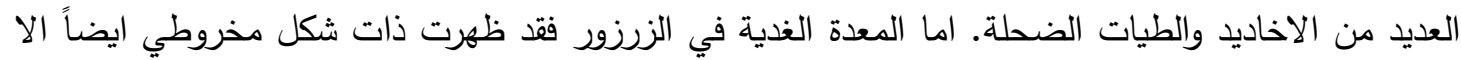

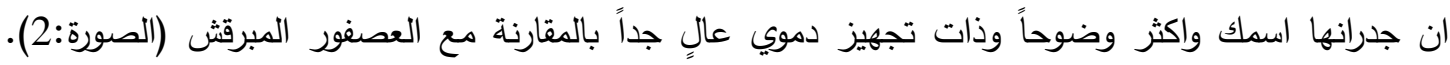
تحوي البطانة الداخلية على طيات واخاديد وتكون اكثر وضوحاً مما في العصفور المبرقش. بينما بينت النتائج النسجية ان جدران المعدة الغدية في طائري البحث تتألف من الطبقات التالية وهي المخاطية، وتحت وضكان المخاطية ، والعضلية الخارجية، والمصلية.

تتكون الطبقة المخاطية للمعدة الغدية في العصفور المبرقش من طيات او بروزات تمتد الى داخل تجويف المعدة تعرف بالحروف المخاطية (Mucosal ridges) تفصل بين هذه الحروف فراغات او مسافات تعرف بالأخاديد Sulcus، وتظهر معظم هذه الحروف مخروطية او مثلثة الثكل ذات نهاية مستديرة (الصور :3،4،6،6). تغطى هذه الحروف بنسيج ظهاري عمودي بسيط ذي خلايا متراصة بشكل كبير جداً وفي

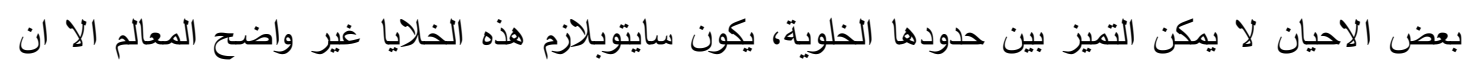

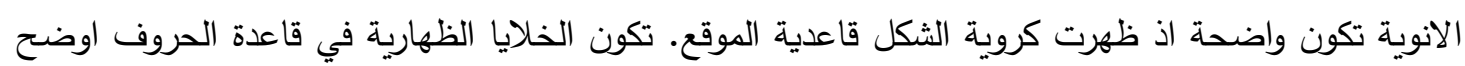
من تلك التي توجد في قمة الحروف نتيجة التحضيرات المجهرية. تستند هذه الخلايا على غشاء قاعدي رقيق

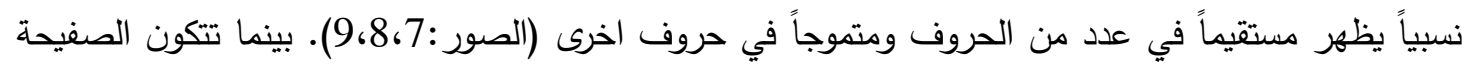

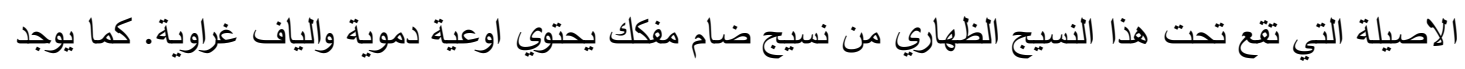

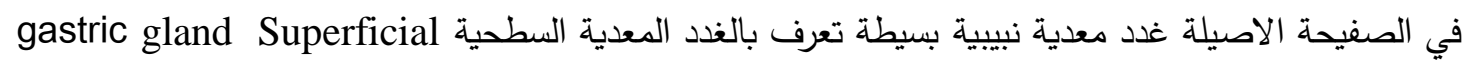
توجد عند قاعدة معظم الحروف المعدية، تكون هذه الغدد كروية الثكل. تتألف من صف واحد من الخلايا

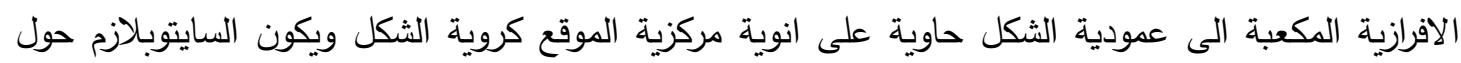

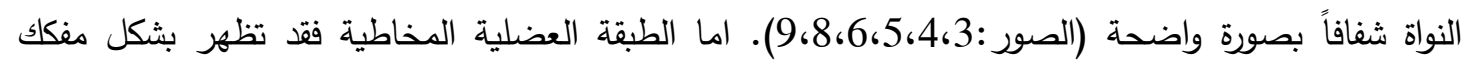

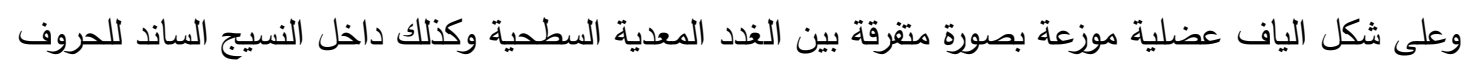

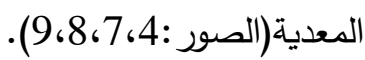

إن الجزء المميز للتركيب النسجي للمعدة الغدية في هذا الطائر هو الطبقة تحت المخاطية اذ كانت جيدة النمو وتشكل معظم جدار المعدة الغدية على حساب الطبقات الاخرى ـ وهي مؤلفة من نسيج ضام مفكك هوك يحتوي على اوعية دموية والياف غراوية. الا ان الجزء الاكثر تميزا في هذه الطبقة هي الغدد المعدية والتي تعرف بالغدد المعدية العميقة Deep Gastric gland وتثكل معظم الطبقة تحت المخاطية وهي غدد حويصلية نبيبية كبيرة الحجم وهي تكون ذات شكلين رئيسين الاول بيضوي او مخروطي، وتكون الغدد البيضوية الشكل

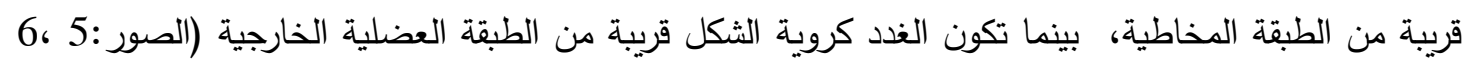

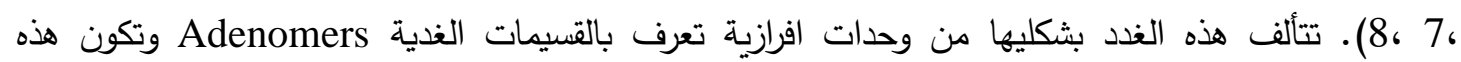

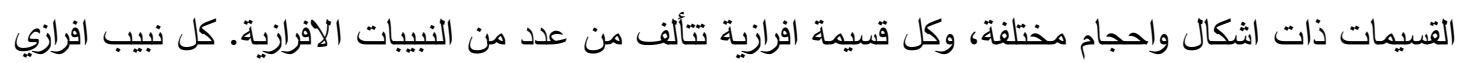
يكون كروي الثكل تقرببا يحتوي على صف واحد من الخلايا التي تكون مكعبة تكون ذات نواة كروية الثكل 
مركزية الموقع تستند هذه الخلايا على غثاء قاعدي سميك نسيباً لأنه يعمل على دعم واسناد وفصل الخلايا

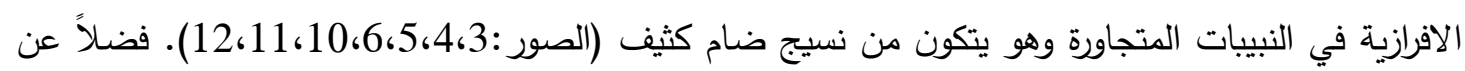
تركيبها المميز فان هذه الغدد تتميز بنظامها القنوي المميز الذي يسهم في ايصال افرازات هذه الغدد بسهولة الى الى تجويف المعدة الغدية. اذ تطرح خلايا النبيبات الافرازية افرازاتها الى تجويف هذه النبيبات والتي تعرف بلتيل بالقناة

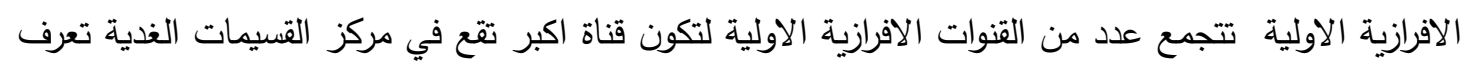

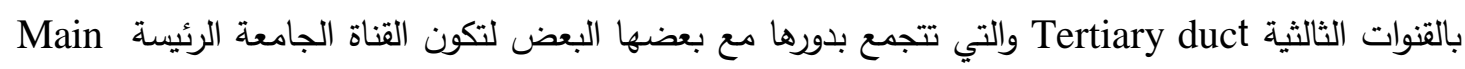
collection duct

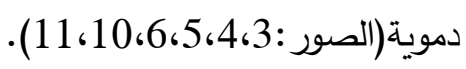

ظهرت الطبقة العضلية خارجية رقيقة نسبياً وهي مؤلفة من طبقتين الاولى دائرية الترتيب والثانية طولية

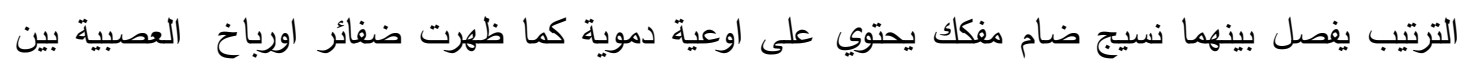
الطبقتين العضليتين الثانويتين. اما الطبقة المصلية فقد ظهرت مؤلفة من نسيج ضام مفكلك يحتوي اوعية دموية

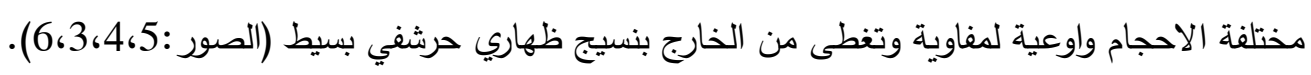
اما المعدة الغدية في الزرزور فقد ظهرت مشابهة لمثيلتها في العصفور المبرقش الا انها أكثر نمواً

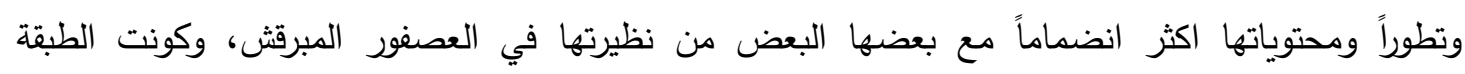

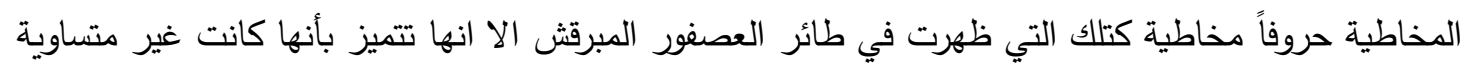

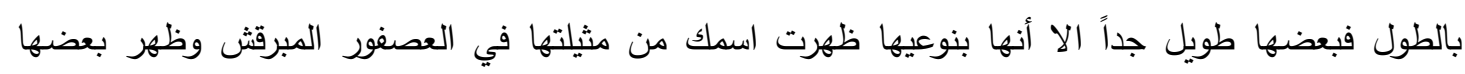

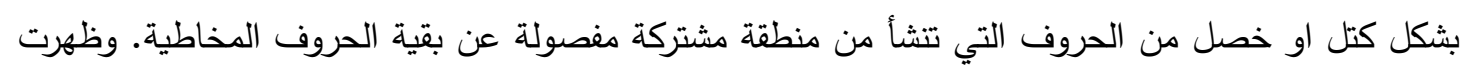

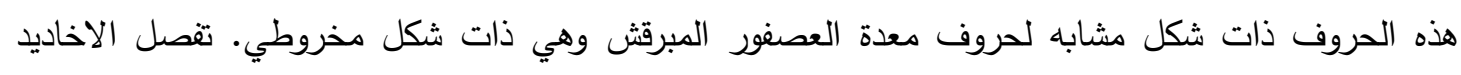
الحروف المخاطية عن بعضها البعض وتكون هذه الاخاديد عميقة بين الحروف الطويلة وقليلة العمق بين الحروف القصيرة (الصور:13،13،16،16). تغطى الحروف بنسيج ظهاري مكعبي بسيط وخلايا متراصة ايضاً بثكل كبير ويصعب التميز بين حدودها بصورة اكبر مما ظهرت في العصفور المبرقث وتكون انويتها كروية

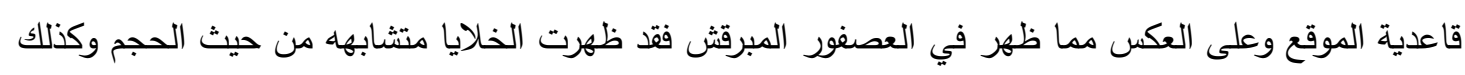

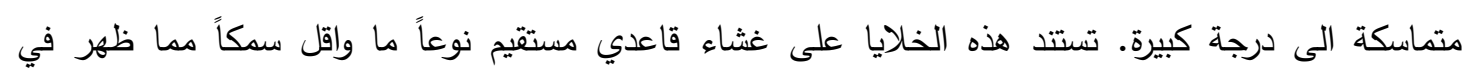

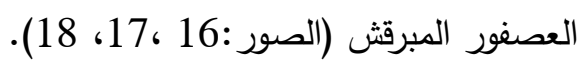

تتألف الصفيحة الاصيلة من نسيج ضام مفكك يحتوي على اوعية دموية والياف غراوية ويمتد هذا

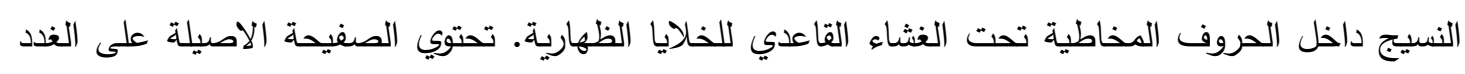
المعدية السطحية اسفل الحروف المخاطية التي ظهرت ايضاً غدد نبيبية بسيطة كروية او بيضوية الثكل وتكون هذه الغدد اقل عدداً مما ظهرت عليه في العصفور المبرقش، تتألف هذه الغدد من صف والفية واحد من الخلايا المكعبة التي تكون ذات حدود خلوية غير واضحة بينما تكون النوى قاعدية الموقع كروية الثكل (الصور :13، 14، 15، 16). تكون العضلية المخاطية اكثر نمواً مما ظهرت عليه في العصفور المبرقش وهي تظهر بشون بشكل

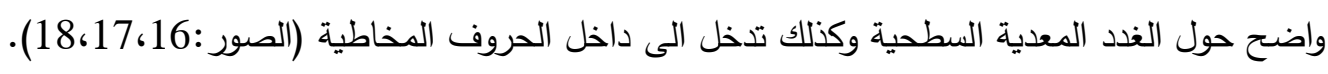
تتألف الطبقة تحت المخاطية من نسيج ضام مفكك يحتوي على اوعية دموية والياف غراوية الا ان

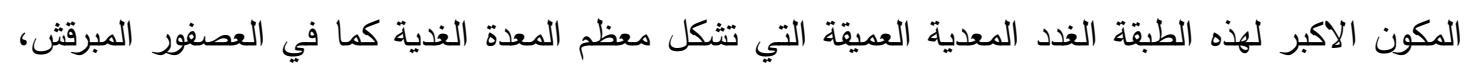

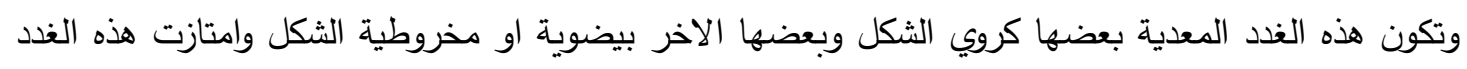


عنها في العصفور المبرقش بأنها اكثر تراصاً مع بعضها البعض ويكون تجويفها كبيراً نسبياً مليئاً بالإفرازات الغدية. وهي مؤلفة من قسيمات غدية ذات اشكال واحجام مختلفة، تتألف هذه القسيمات من النبيبات الغدية التي نئي

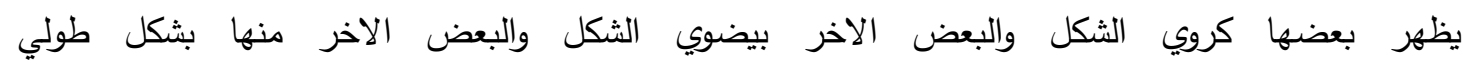

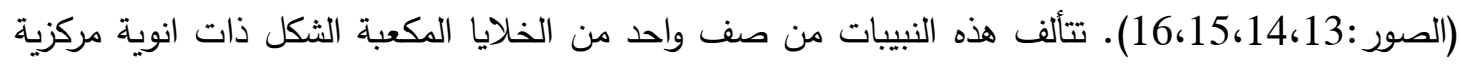
كروية الثكل. وتمتاز هذه الخلايا عنها في العصفور المبرقش بانها اكثر عددا وتراصا. تستتد هذه الخلايا على منى غشاء قاعدي رقيق مشترك بين النبيبات المتجاورة وهو اقل سمكا مما ظهر عليه في العصفور المبرقش كما انه

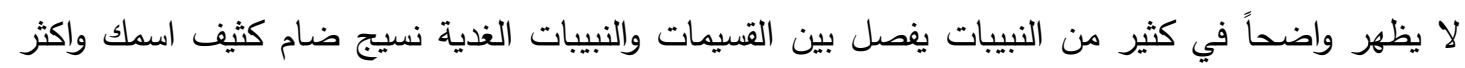

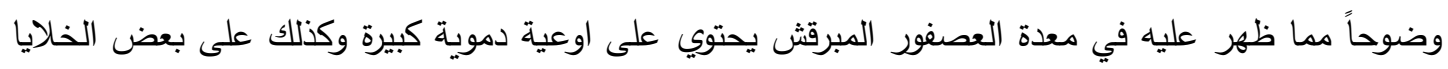
(الصور:19،20،21)، يكون النظام القنوي الخاص بهذه الغدد مشابه لما ظهر عليه في معدة العصفور المبرقش فهو مؤلف من قنوات افرازية اولية وثالثية وقنوات رئيسة الا ان عدداً من القسيمات الافرازية تطرح

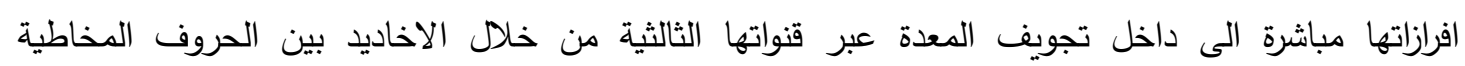

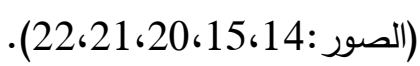

الطبقة العضلية الخارجية ظهرت مماثلة لنظيرتها في العصفور المبرقش الا انها تكون اسمك منها،

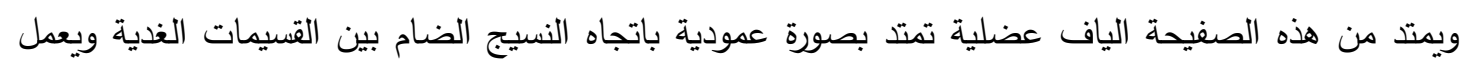
معها على دعم واسناد هذه القسيمات، يفصل بين الطبقتين نسيج ضام يحتوي على اوعية دموية وكذلك ظهرت

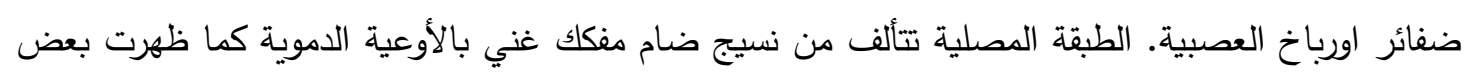
الاعصاب في هذه الطبقة وتغطى من الخارج بنسيج ظهاري حرشفي بسيط (الصور :13،15،15). اما بالنسبة لكيمياء النسج المخاطين للمعدة الغدية فقد اظهر النسيج استجابة موجبة لجميع التقنيات المستعملة الا ان هذه الاستجابة اختلفت من تقنية الى اخرى ومن طائر الى اخر · وقد اظهر النسيج الظهاري

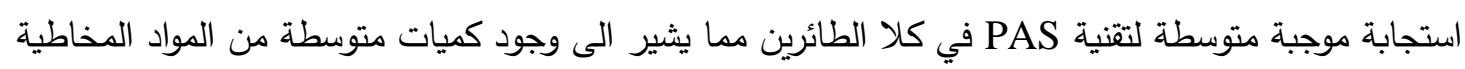
الموجبة لتقنية PAS. اما بالنسبة لتقنية TB فقد ظهر النسيج الظهاري استجابة موجبة شديدة في العصفور المبرقش وموجبة متوسطة في الزرزور مما يدل على وجود كميات كبيرة نسبياً من السكريات المتعددة المخاطية الحامضية في كلا الطائرين. في حين اظهر النسيج الظهاري في العصفور المبرقش استجابة موجبة قوية لتقنية AB PH 2.5 لنفس التقنيتين على التوالي وهذا يدل على تفاوت في افراز وتوزيع المواد المخاطية المكبرتة ذات الحامضية

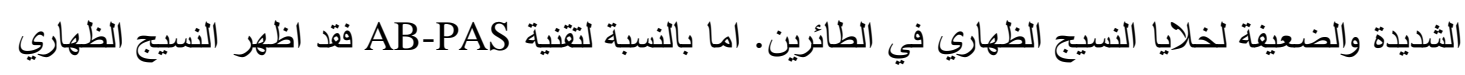
في العصفور المبرقش استجابة موجبة شديدة، في حين اظهر النسيج الظهاري في الزرزور استجابة متوسطة

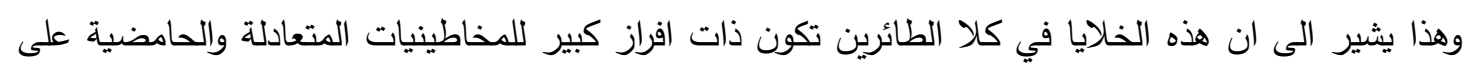

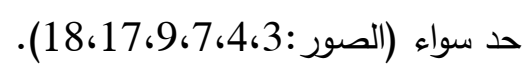

اما بالنسبة للغدد المعدية السطحية والتي ظهرت في الصفيحة الاصيلة للطائرين. فقد اظهرت استجابة

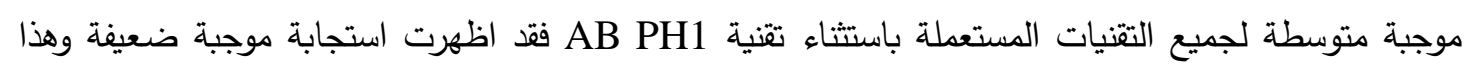
يشير الى ان هذه الغدد تكون ذات افراز مخاطاني عالٍ وهي تثترك بصورة واضحة في تكوين المواد المخاطية

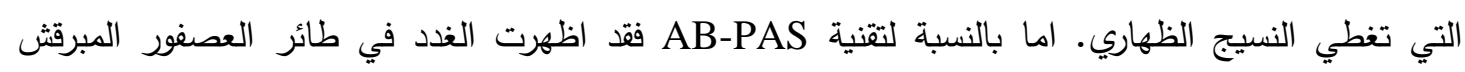
الاستجابة في مركز الغدة اي ان الخلايا الافرازية لهذه الغدد لم يظهر عليها اي استجابة بينما كانت المواد 
المخطانية المتعادلة والحامضية موجودة في مركز الغدة بينما اظهرت خلايا هذه الغدد في الزرزور استجابة

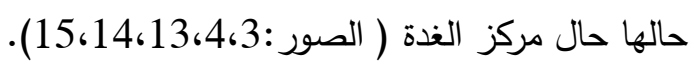

واظهرت الغدد المعدية العميقة في الطبقة تحت المخاطية استجابات متباينة للتقنيات المستخدمة في

كلا الطائرين اذ اظهرت استجابة موجبة متوسطة في العصفور المبرقش وموجبة قوية في الزرزور لتقنية PAS

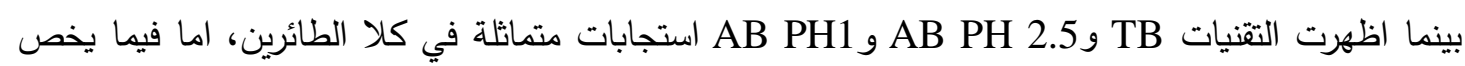
تقنية AB-PAS فقد اظهرت استجابات موجبة قوية في العصفور المبرقش وموجبة متوسطة في الزرزور الا ان

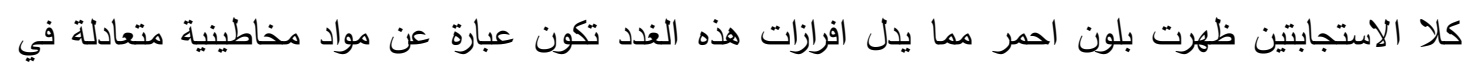
الغالب وفي كلا الطائرين، الا ان من النتائج المهمة والملفتة للنظر في هذه الغدد ولكل التقنيات المستعملة وفي كلا الطائرين هي ان المواد المكتشفة بهذه التقنيات ظهرت موجودة بشكل رئيسي في القنوات الثالثية والقنوات الناقلة الرئيسة بينما تكون الوحدات الافرازية لهذه الغدد خالية من الافراز وهذا يشير الى سرعة تفريغ محتويات

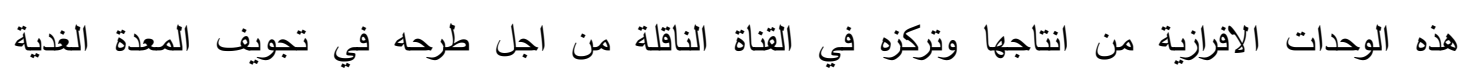

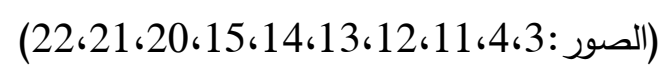

\section{المناقثة}

ظهرت المعدة الغدية في كلا الطائرين مخروطية او شبه مستطيلة في العصفور المبرقش الثكل قمتها باتجاة المريء وقاعدتها باتجاه القانصة ذات نشاط افرازي كيميائي وهذا يتقق مع معدة طائر القطا الغدية ومعدة الغئية البيغاء المتيمة، وطائر الزاغ، [11،12،13]. كما ظهرت الطبقة المخاطية للمعدة الغدية لطائري البحث مكونة

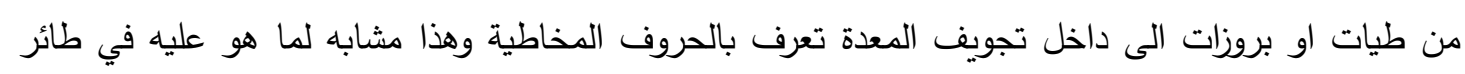

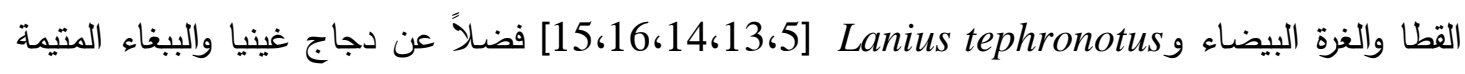
وطائر الزاغ [12،11] . تغطى هذه الطيات في معدة العصفور المبرقش بنسيج ظهاري عمودي بسيط ذي خلايا

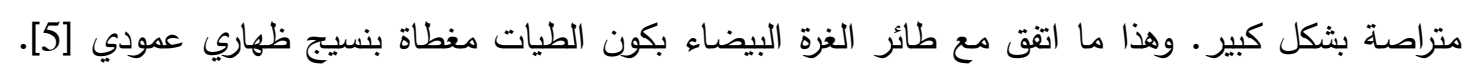

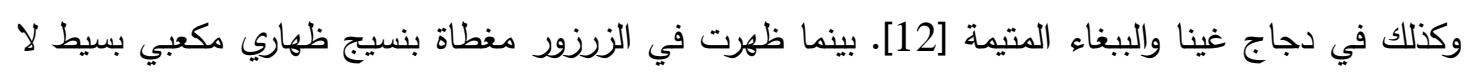
يمكن تمييز حدودها بوضوح. بينما تتكون الصفيحة الاصيلة في كلا طائري البحث التي تقع تحت هذا النسيج

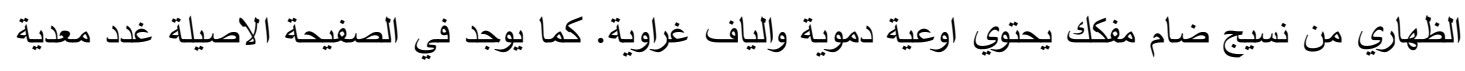

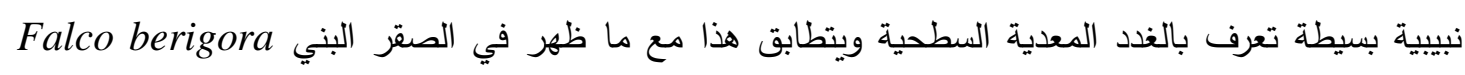

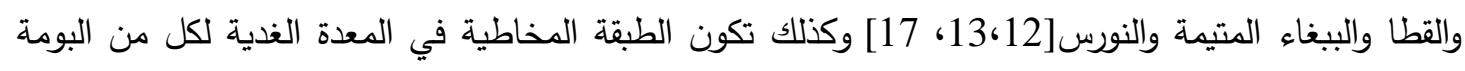
البيضاء وحمامة الغابات غنية بغدد انبوبية بسيطة، السطحية فيها طويلة وواسعة في البومة البيضاء مقارنة بما

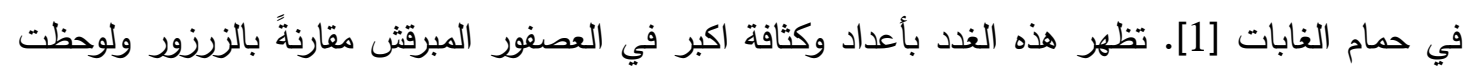

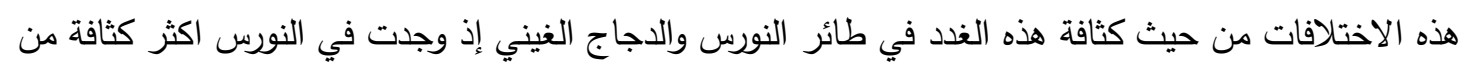

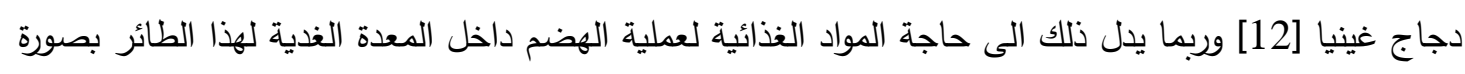
اكبر منها في الزرزور • تتألف هذه الغدد من صف واحد من خلايا مكعبة الى عمودية الشكل ذات انوية كروية

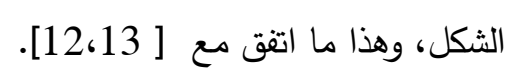

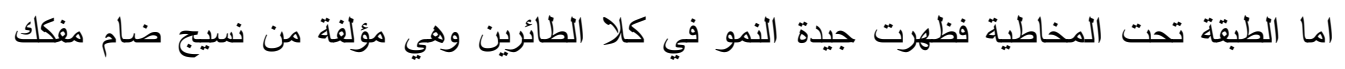
يحتوي على اوعية دموية والياف غراوية. الا ان الجزء الاكثر تميزا في هذه الطبقة هي الغدد المعدية والتي 
تعرف بالغدد المعدية العميقة وتثكل معظم الطبقة تحت المخاطية وهي غدد حويصلية نبيبية كبيرة الحجم وتكون هذه الغدد ذات شكلين رئيسين بيضوي او مخروطي وهذا ماظهر في حمامة الغابات، والبومة البيضاء والقطا والببغاء المتيمة [1، 12، 13]. تكون هذه الغدد مكونة من وحدات افرازية تعرف بالقسيمات الغدية وتكون ذات

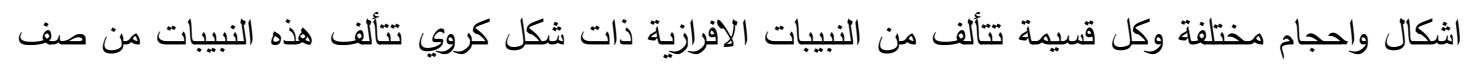
من خلايا مكعبة الثكل ويتطابق هذا مع عدة طيور [12،13]، وكذلك ظهر نظام قنوي مشابه في دجاج الماء .[18] Gallinula chloropuz

الطبقة العضلية ظهرت في طائري البحث رقيقة مكونة من طبقتين الاولى دائرية الترتيب والثانية

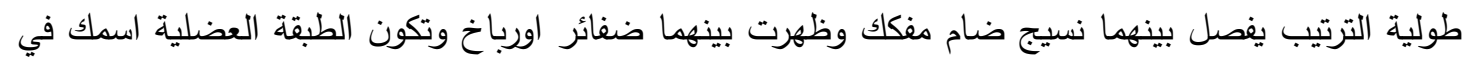

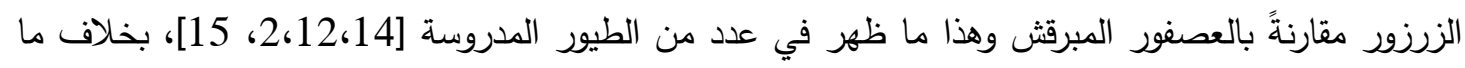
ظهر في دجاج غينيا والببغاء المتيمة والنورس [10]. اذ ظهرت الطبقة العضلية في النورس والببغاء المتيمة ودجاج غينيا مكونة من ثلاث طبقات، الداخلية عضلات ملساء دائرية والثانية عضلات ملساء طولية والخارجية عضلات ملساء دائرية وتكون هذه الطبقة أكثر سمكاً في النورس منها في النوعين الآخرين. وكذلك في الصقر فلراء البني Falco berigora تتكون الطبقة العضلية من ثلاثة طبقات هي داخلية وخارجية طولية رقيقة وطبقة

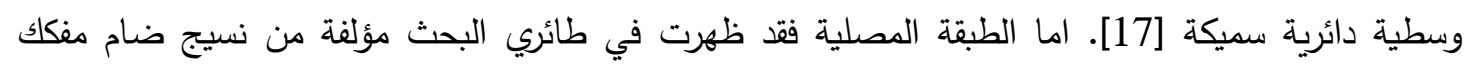
يحتوي على اوعية دموية مختلفة الاحجام واوعية لمفاوية وتغطى من الخارج بنسيج ظهاري حرشفي بسيط. كما في طائر القطا [13].

اما من الناحية الكيميائية النسجية كانت الاستجابة موجبة تتراوح مابين متوسطة وشديدة حسب طبقات

المعدة لتقنية PAS و (AB PH 1-2.5) وهذا توافق مع [2، 13، 19]، وبينت نتائج البحث الحالي استجابة موندية موجبة باستعمال تقنية AB-PAS ان النسيج الظهاري للمعدة الغدية يحتوي على المخاطين الحامضي والمتعادل

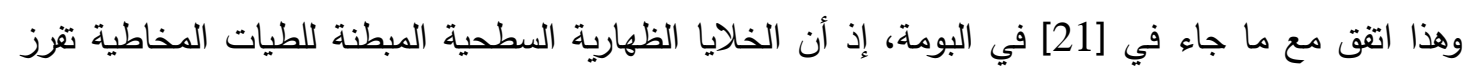

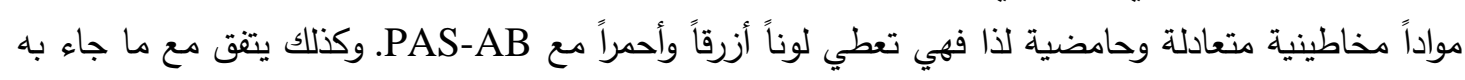
[7] في طائر السمان من نوع C. coturnix إذ أشار إلى أن الغدد المعدية تحوي مخاطينيات متعادلة

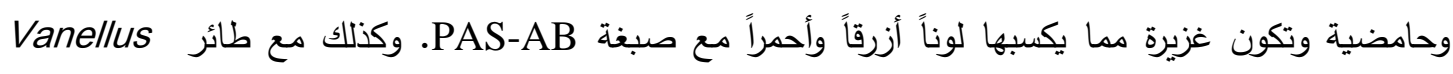

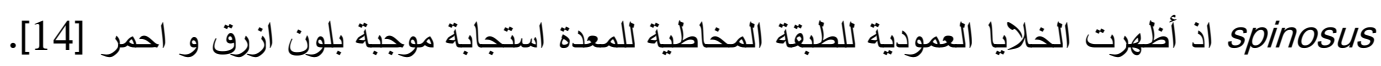


جدول (1) يبين ابعاد التراكيب التابعة للمعدة الغدية لكلا الطائرين

\begin{tabular}{|c|c|c|}
\hline الزيزور & العصفور المبرقش & التراكيب \\
\hline مخروطية & مخروطية او متطاولة & شكل المعدة \\
\hline 1.5 سم & 0.5 سم & طول المعدة \\
\hline 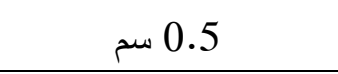 & 0.15 سم & قطر المعدة \\
\hline & & الطبقة المخاطية \\
\hline 48.3132 مايكروميتر & 29.5091 مايكروميتر & سمك الحروف المخاطية \\
\hline 11.2201 مايكروميتر & 9.7111 مايكروميتر & طول الخلايا الظهارية \\
\hline 6.7068 مايكروميتر & 8.7345 مايكروميتر & سمك الخلايا الظهارية \\
\hline 2.1949 مايكروميتر & 2.2971 مايكروميتر & سمك الغشاء القاعدي \\
\hline & & الصفيحة الاصيلة \\
\hline 31.5404 مايكروميتر & 29.1196 مايكروميتر & قطر الغدد المعدية السطحية \\
\hline 4.8555 مايكروميتر & 1.8285 مايكروميتر & قطر الانوية المركزية \\
\hline & & الطبقة تحت المخاطية \\
\hline 915.9259 مايكروميتر & 339.703 مايكروميتر & قطر الغدد المخروطية \\
\hline 433.7711 مايكروميتر & 214.2262 مايكروميتر & قطر الغدد الكروية \\
\hline 110.9259 مايكروميتر & 112.3703 مايكروميتر & قطر القسيمات \\
\hline 50.9629 مايكروميتر & 33.8996 مايكروميتر & قطر النبيبيب الافرازي \\
\hline 6.3394 مايكروميتر & 10.7293 مايكروميتر & طول الخلايا المبطنة له \\
\hline 3.0487 مايكروميتر & 4.5108 مايكروميتر & قطر الانوية \\
\hline & & الطبقة العضلية الخارجية \\
\hline 44.154 مايكروميتر & 18.6588 مايكروميتر & سمك الطبقة الدائرية \\
\hline 67.9367 مايكروميتر & 55.4821 مايكروميتر & سمك الطبقة الطولية \\
\hline & & الطبقة المصلية \\
\hline$\|I\| I$ & 16.9876 مايكروميتر & الاوعية الدموية \\
\hline
\end{tabular}


جدول (2) يبين النتائج الكيميائية النسجية للمعدة الغدية في طائري العصفور المبرقش والزرزور

\begin{tabular}{|c|c|c|c|c|c|c|}
\hline \multicolumn{3}{|c|}{ الزرزور } & \multicolumn{3}{|c|}{ العصفور المبرقش } & \multirow[t]{3}{*}{ التقنية } \\
\hline الطبقة تحت & الصفيحة & النسيج الظهاري & الطبقة تحت & الصفيحة & النسيج الظهاري & \\
\hline مخاطية & الاصيلة & & مخاطية & الاصيلة & & \\
\hline+++ & +++ & ++ & ++ & ++ & ++ & PAS \\
\hline++ & ++ & ++ & ++ & ++ & +++ & TB \\
\hline++ & + & + & ++ & ++ & +++ & $\mathrm{AB} \mathrm{pH} 1$ \\
\hline+++ & ++ & ++ & +++ & ++ & +++ & $\mathrm{AB} p H 2.5$ \\
\hline++ & ++ & ++ & +++ & ++ & ++ & AB -PAS \\
\hline
\end{tabular}

\section{References المصادر}

1. Al-Juboory, R.W; Dauod, H. A. M, A. S.. Ibn Al-Haitham J. Pure \& Appl. Sci. Vol. 29 (2):1-12. (2016).

2. Hamdi, H.; EL-Ghareeb, A.; Zaher, M. and AbuAmod, F. Inter. J. of Sci. \& Eng. Res.4ISSN 2229-5518. (2013)

3. Liman, N.; Alan, E. and Bayram, G.K. J. Anatomy. 217:57-66. (2010)

4. Martínez, A.; López, J. and Sesma, P. J. Histochem.32: 63-70. (2000)

5. Batah, A. L.; Selman, H. A. and Saddam, M. Diyala Agri. Sci. J. Vol 4 (1): 9 - 16. (2012)

6. Selvan, P. S. ; Ushakumary, S. and Ramesh, G. Int. J. Poult. Sci.7: 1112- 1116. (2008).

7. Zaher, M.; Ghareep, A.W. E.; Hamdi, H. and AbuAmed, F. Lif. Scie. J.9(3): 201. (2012).

8. Frank, H. The Golden Book of Australian birds and mammals. Illustrated by Tony Oliver. Golden Press. p. 44. ISBN 0-7302-0011. (1985).

9. Higgins, P. J.; Peter, J. M. and Cowling, S. J. eds. Handbook of Australian‘ New Zealand، and Antarctic Birds. Volumes 7: Boatbill to Starlings. Melbourne: Oxford University Press. ISBN 0-19-553996-6. (2006)

10. ALHajj, H. A.,"optical microscopy preparations" 1st Ed. Aman- Jourdan (2010).

11.Hamd, R. S.M.,M. Sc. Thesis College of Science, University of Tekrit.(2008)

12. Al-hamadany, A. M. T. A. Ph.D. Dissertation. College of Education. Mosul University (2012).

13. AL- Jeraisy.F.N.N, M.Sc. College of Education of pure Science. Mosul University.(2017)

14. Kadhim, K.; Zuki, A.; Noordin, M. and Babjee, S.. Anat. Histol. Embryozl. 40(3): 226-233. (2011).

15. Rossi, J. R.; Baraldi, S. M.; Oliveira, D.; da Cruz، C.; Franzo, V. S. and Sagula, A. Cienc. Rural. 35:1319-1324. (2005). 
16. ZHU, L. Int. J. Morphol. 33(2): 459-464. (2015).

17.Al-taee, A. A.. Babylon J. for Pure and Appl Sci. Vol. 25 (3).PP:915-936. (2017).

18. Jassem, E. S.; Hussein, A. T. and Sawad, A. A. Bas.J.vet.Res.14(4):73-82. (2016).

19.Fatma, M. A. and Taki-El-Deen..The Egyptian. J. of Hos. Med. Vol. 67(1): 314321. (2017).

20. El-Sayyad, I. H.. J. Egypt. Ger. Soc. Zool. 16(C): 185-202، 1995. (1995). 
الصورة (1): صورة فوتوغرافية لمعدة العصفور المبرقش تبين المعدة الغدية PRO؛ والمعدة العضلية GI، والبرزخ IS.

الصورة (2): صورة فوتوغرافية لمعدة الزرزور تبين المعدة الغدية PRO، والبرزخ IS، والقانصة GI. الصورة (3): مقطع عرضي في المعدة الغدية للعصفور المبرقش يوضح، الحروف المعدية MR، الغدة المعدية السطحية SGG، النسيج الظهاري العمودي البسيط SCT، والصفيحة الاصيلة LPR، القناة الجامعة الريسٔية MD، القنوات الثالثية TD، وعاء دموي BV، الوحدة الفارزة SU، الغدة المعدية العميقة DGG، القنوات الاولية PD، القسيمة الغدية AD، ظفائر اورباخ AP، الطبقة العضلية الخارجية SUS، SE SE، لاحظ الاستجابة الموجبة لهذه التقنية (الاسهم). (تقنية .(AB-PAS

الصورة (4): مقطع عرضي في المعدة الغدية للعصفور المبرقش يوضح، الحروف المعدية MR، الغدة المعدية

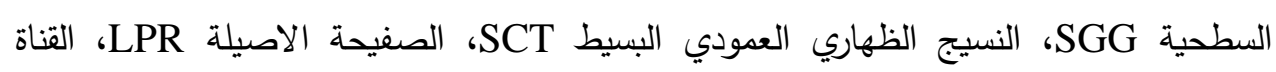

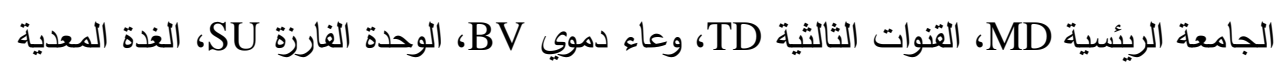

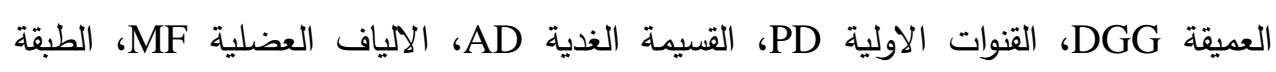
العضلية الخارجية MUS ، الطبقة المصلية SE لاحظ الاستجابة الموجبة لهذه التقنية (الاسهم).

(PAS تقنية)

الصورة (5): مقطع عرضي في المعدة الغدية للعصفور المبرقش يوضح، الحروف المعدية MR، الغدة المعدية

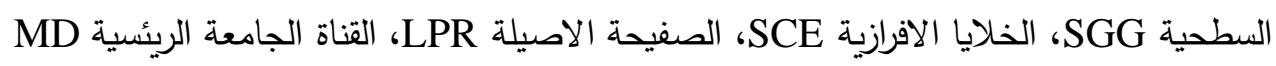

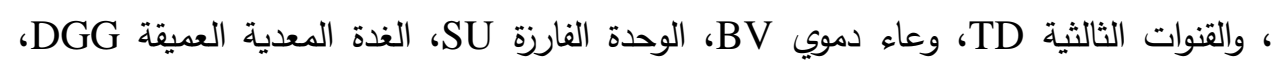

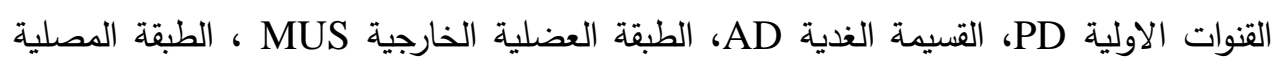

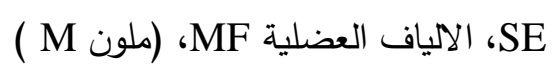

الصورة (6): مقطع عرضي في المعدة الغدية للعصفور المبرقش يوضح، الحروف المعدية MR، الغدة المعدية

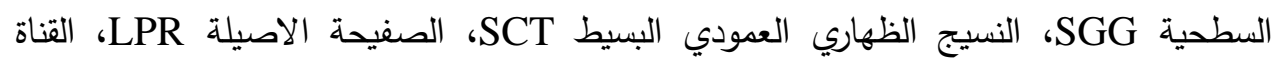

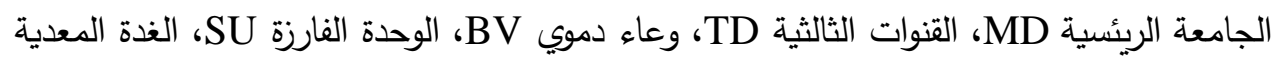

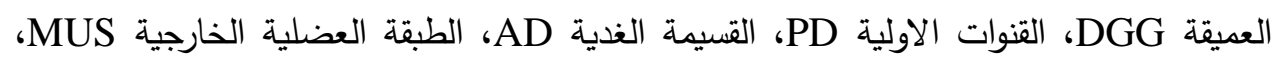

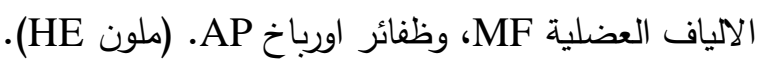

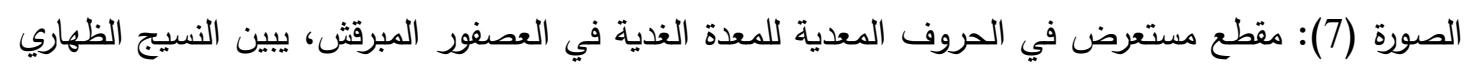

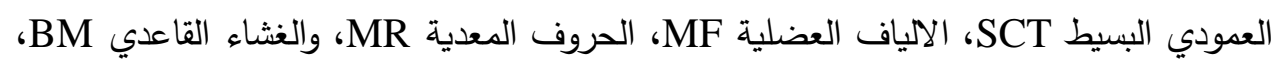
لاحظ الاستجابة الموجبة لهذه التقنية (الاسهم). (تقنية SB-PAS). الصورة (8): مقطع مستعرض في الحروف المعدية للمعدة الغدية في العصفور المبرقش، يبين النسيج العمودي لإنية

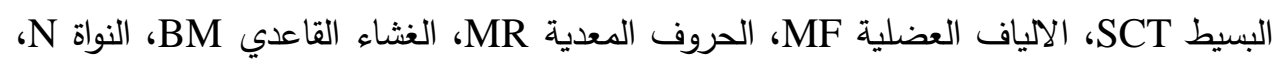

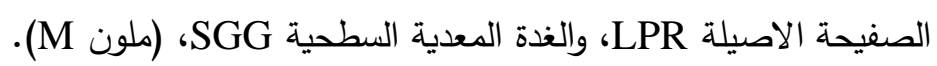


امير محمود طه الحمداني و عبدالعزيز صبحي عزيز الاليمي
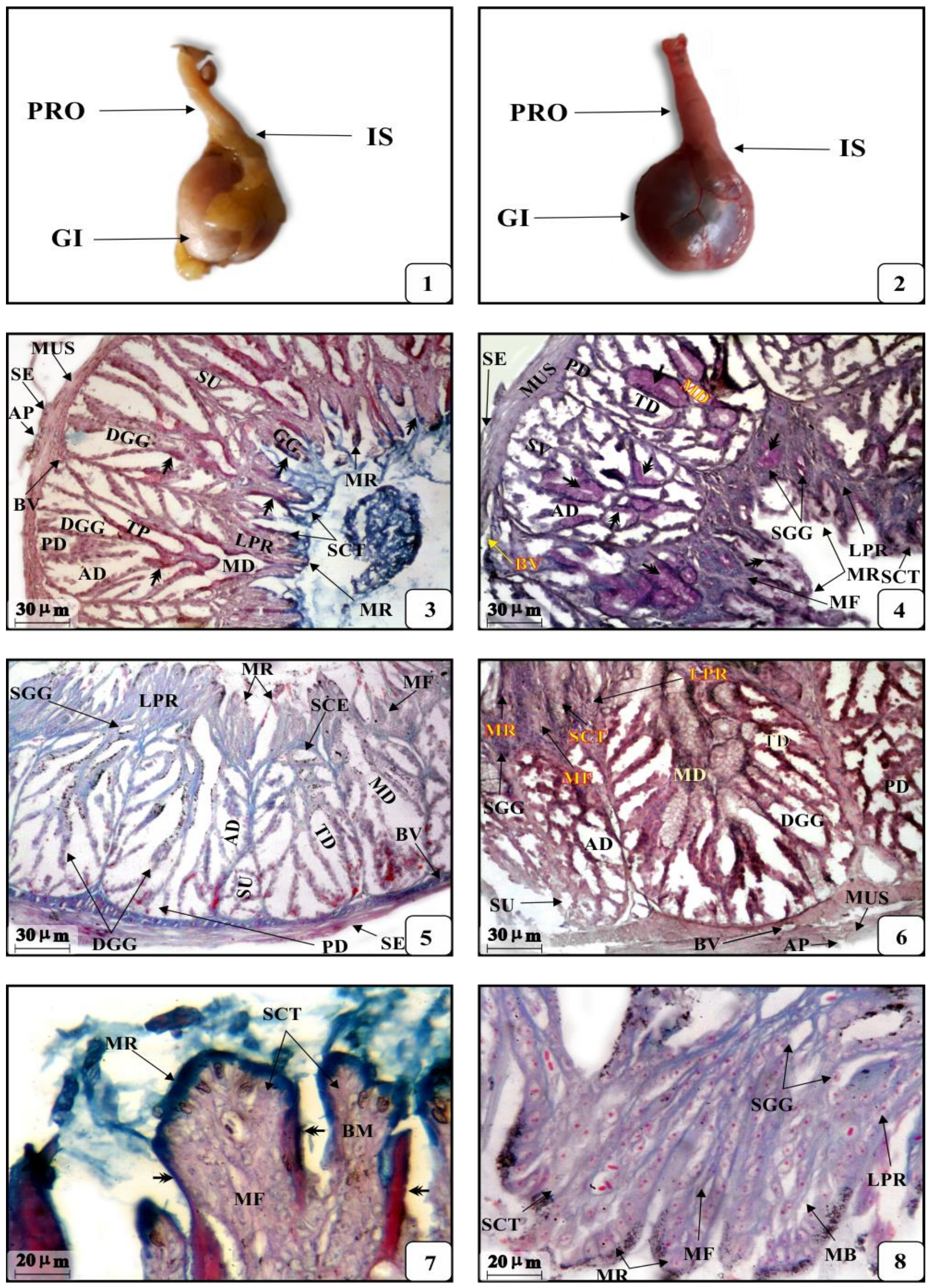
الصورة (9): مقطع مستعرض في الحروف المعدية للمعدة الغدية في العصفور المبرقش، يبين النسيج العمودي

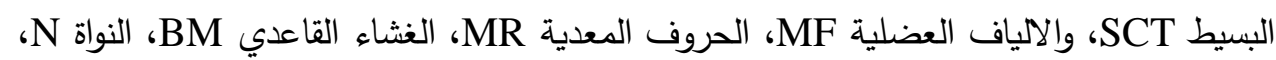
الصفيحة الاصيلة LPR، الغدة المعدية السطحية SGG لاحظ الاستجابة الموجبة لهذه التقنية

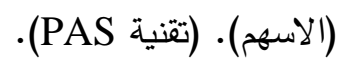

الصورة (10): مقطع مستعرض في الغدة المعدية العميقة في العصفور المبرقش يبين الوحدات الافرازية SU،

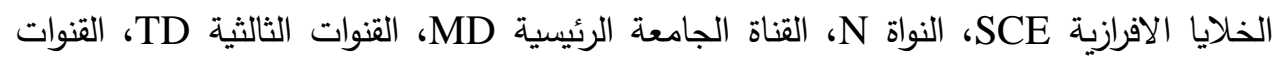

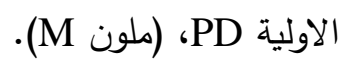

الصورة (11): مقطع مستعرض في الغدة المعدية العميقة في العصفور المبرقش يبين الوحدات الافرازية SU،

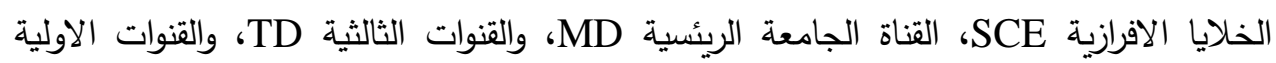
PD القسيمة الغدية AD، الغدة المعدية العميقة DGG، لاحظ الاستجابة الموجبة لهذه التقنية

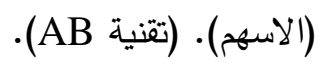

الصورة (12): مقطع مستعرض في الغدة المعدية العميقة في العصفور المبرقش يبين الوحدات الافرازية SU،

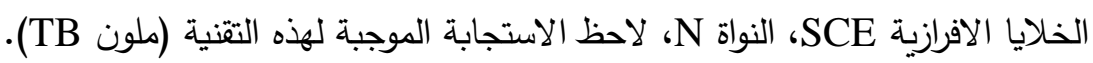

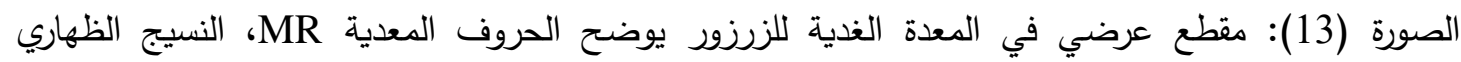

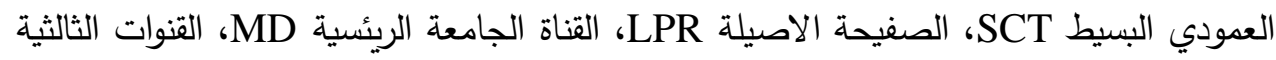
TD، القنوات الاولية PD، القسيمة الغدية AD، الطبقة تحت المخاطية SUB، الغدد المعدية

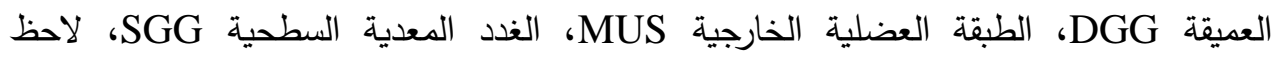
الاستجابة الموجبة لهذه التقنية (الاسهم). (تقنية AB). الصورة (14): مقطع عرضي في المعدة الغدية للزرزور يوضح الحروف المعدية MR، النسيج العمودي البسيط

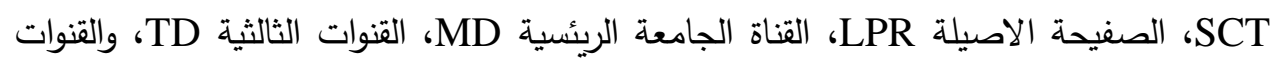
الاولية PD، والقسيمة الغدية AD، والطبقة تحت المخاطية SUB، والغدد المعدية العميقة

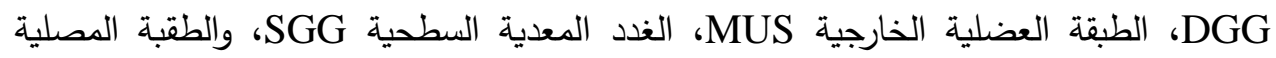
SE الصورة (15): مقطع عرضي في المعدة الغدية للزرزور يوضح الحروف المعدية MR، النسيج العمودي البسيط

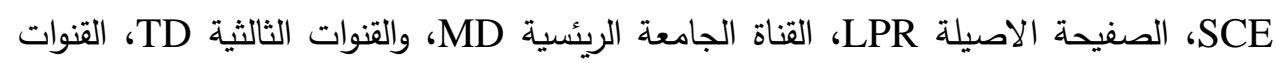

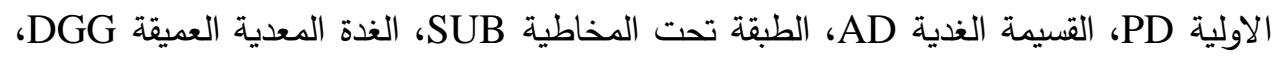
الطبقة العضلية الخارجية MUS، والغدة المعدية السطحية SGG، والاعصاب NE، ND، والطبقة المصلية SE، لاحظ الاستجابة الموجبة لهذه التقنية (الاسهم). (ملون TB).

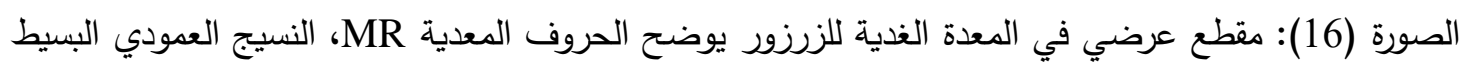

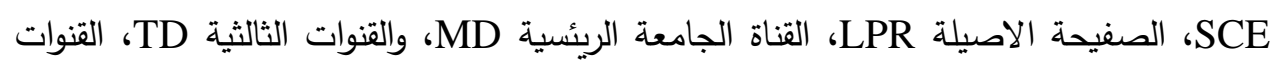

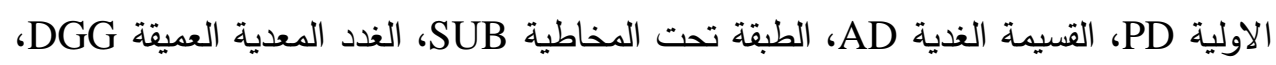

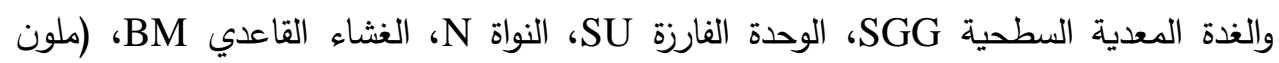


اميز محمود طه الحمداني و عبدالعزيز صبحي عزيز الاليمي
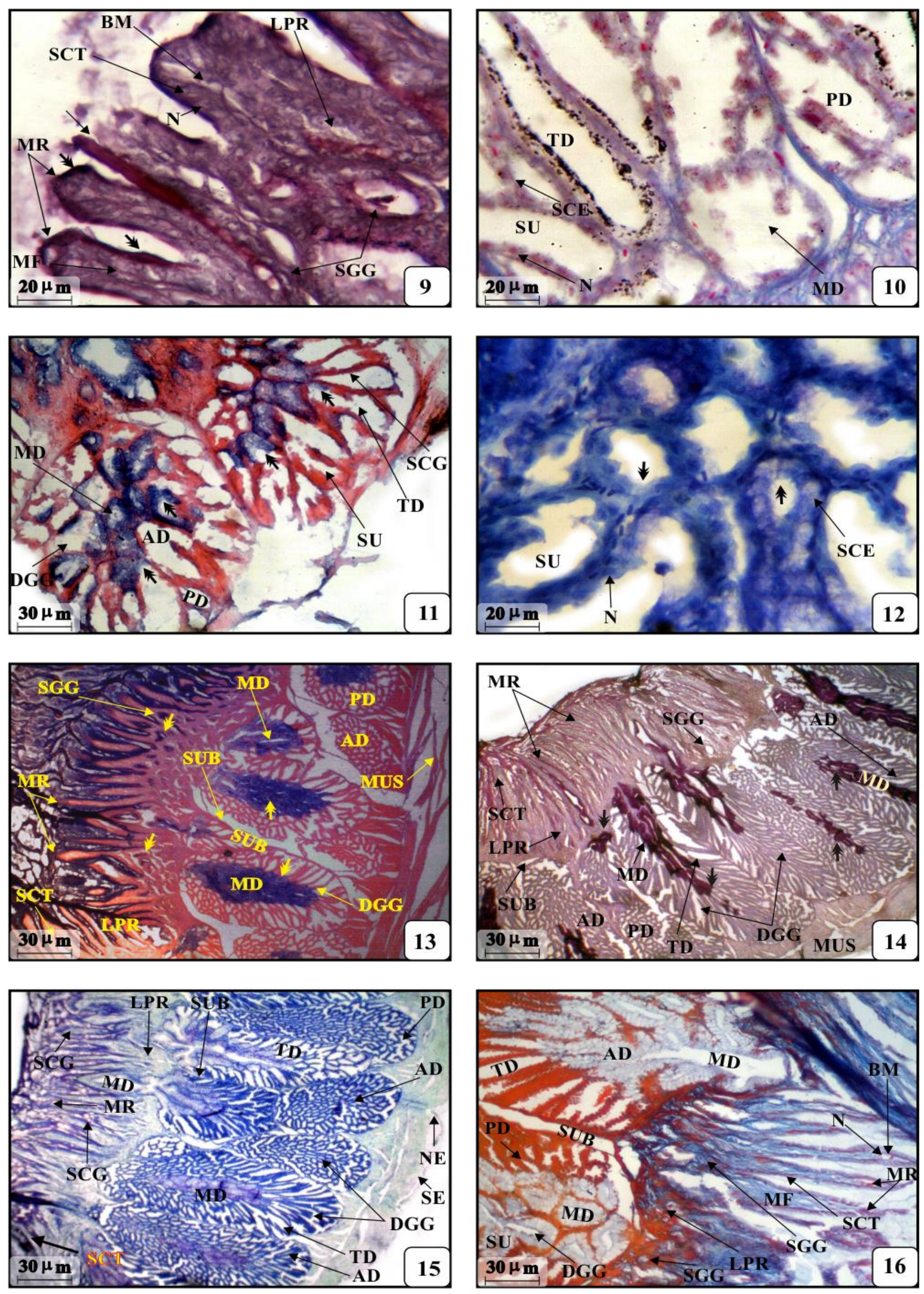
الصورة (17): مقطع مستعرض في الحروف المعدية للمعدة الغدية للزرزور، يوضح النسيج الظهاري العمودي

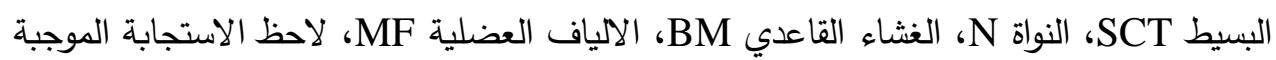

$$
\text { لهذه التقنية (الاسهم). (تقنية PAS) }
$$

الصورة (18): مقطع مستعرض في الحروف المعدية للمعدة الغدية للزرزور ، يوضح النسيج الظهاري العمودي البسيط SCT، النواة N، الغشاء القاعدي BM، الألياف العضلية MF، لاحظ الاستجابة الموجبة

$$
\text { لهذه التقنية (الاسهم). (ملون TB) }
$$

الصورة (19): مقطع مستعرض في الغدد المعدية العميقة للزرزور، يوضح الوحدات الافرازية SU، الخلايا

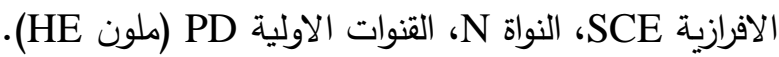

الصورة (20): مقطع مستعرض في الغدد المعدية العميقة للزرزور، يوضح الوحدات الافرازية SU، الخلايا

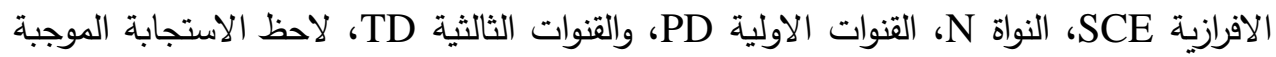
لهذه التقنية (الاسهم). (تقنية PAS).

الصورة (21): مقطع مستعرض في الغدد المعدية العميقة للزرزور، يوضح الوحدات الافرازية SU، الخلايا

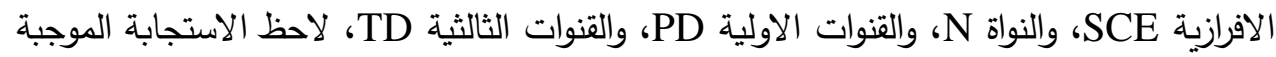
لهذه التقنية (الاسهم). (ملون TB).

الصورة (22): مقطع مستعرض في الغدد المعدية العميقة للزرزور، يوضح الوحدات الافرازية SU، الخلايا الافرازية SCE، النواة N، القنوات الاولية PD، والقنوات الثالثية TD، والقنوات الجامعة الرئيسية MD، لاحظ الاستجابة الموجبة لهذه التقنية (الاسهم). (تقنية AB- PAS ). 
اميز محمود طه الحمداني و عبدالعزيز صبحي عزيز الاليمي
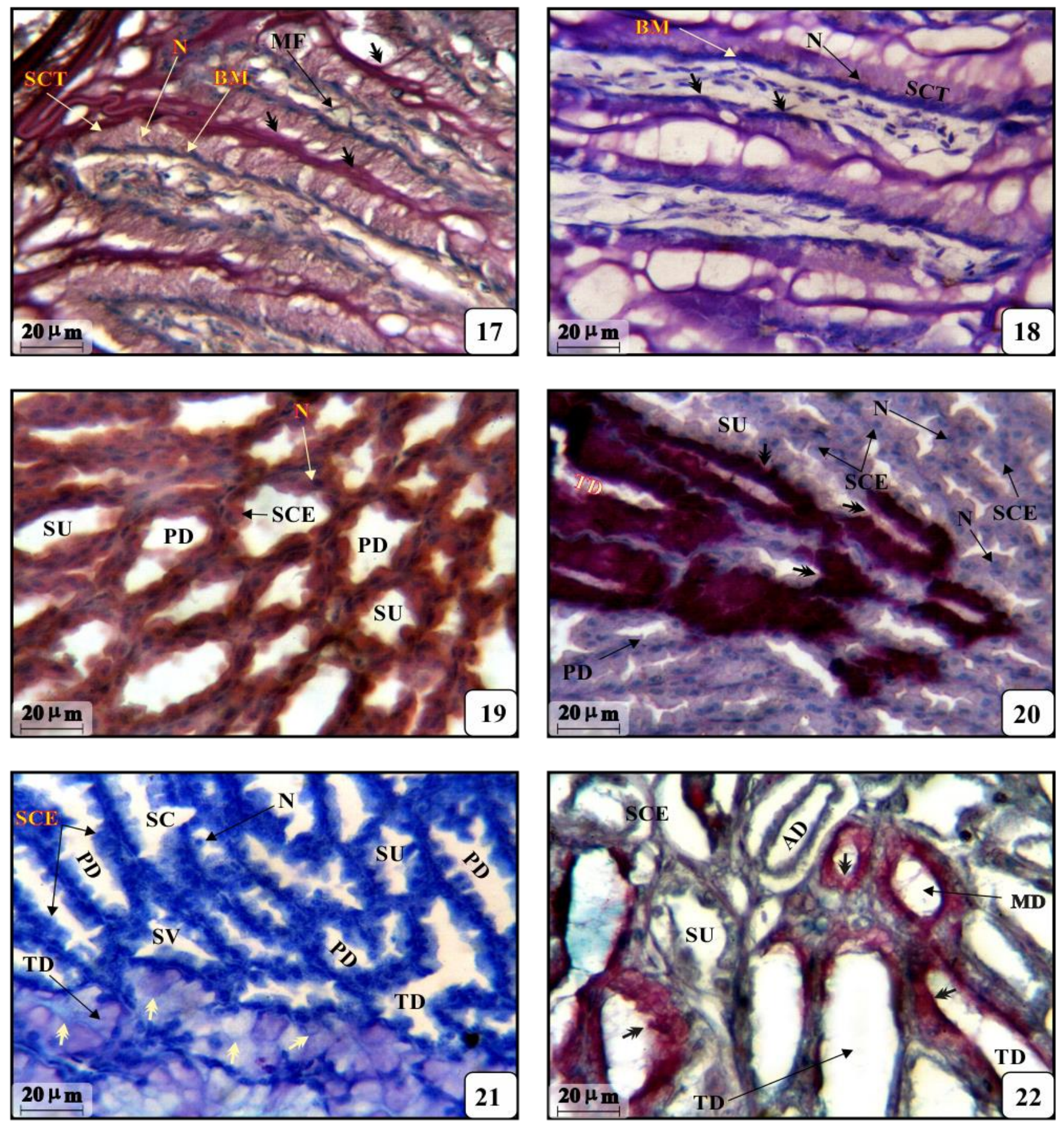